\title{
Management and outcome of traumatic subdural hematoma in 47 infants and children from a single center
}

\author{
Harald Binder - Thomas M. Tiefenboeck · Marek Majdan · Micha Komjati · Rupert Schuster · Stefan Hajdu • \\ Johannes Leitgeb
}

Received: 26 September 2018 / Accepted: 27 March 2020 / Published online: 24 April 2020

(c) The Author(s) 2020

\begin{abstract}
Summary
Background Traumatic brain injury (TBI) is a frequent cause of mortality and acquired neurological impairment in children. It is hypothesized, that with the adequate treatment of SDH in children and adolescence, excellent clinical and functional outcomes can be achieved. The aim of this study was to present the severity and outcome of traumatic SDH in children and adolescence as well as to analyze differences between patients treated surgically and conservatively. Methods In this study 47 infants and children with a subdural hematoma (SDH) were treated between 1992 and 2010 at a single level-one trauma center. Data regarding accident, treatment and outcomes
\end{abstract}

\section{Availability of data and material The datasets generated and/or analyzed during the current study are not publicly available due to data privacy but are available from the corresponding author on reasonable request. \\ Investigation performed at the Department of Trauma Surgery, Medical University of Vienna, Vienna General Hospital, Vienna, Austria}

Electronic supplementary material The online version of this article (https://doi.org/10.1007/s00508-020-01648-3) contains supplementary material, which is available to authorized users.

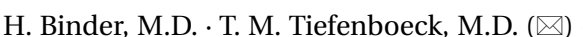

R. Schuster, M.D. · S. Hajdu, M.D. · J. Leitgeb, M.D.

Department of Orthopaedics and Trauma Surgery,

Division of Trauma Surgery, Medical University of Vienna,

Waehringer Guertel 18-20, 1090 Vienna, Austria

thomas.tiefenboeck@meduniwien.ac.at

M. Komjati, MBBS

Department of Orthopaedics, Sacred Heart Hospital of Jesus, Vienna, Austria

M. Majdan, $\mathrm{PhD}$

International Neurotrauma Research Organization, Vienna, Austria were collected retrospectively. To classify the outcomes the Glasgow outcome scale (GOS) scores at hospital discharge and at follow-up visits were used. Severity of SDH was classified according to the Rotterdam score.

Results In total, 47 cases were treated (21 surgically, 26 conservatively), with 10 patients needing delayed surgery. Overall, $89 \%$ of the patients were able to leave hospital, 5 patients died, 2 patients $(5 \%)$ within $24 \mathrm{~h}$, another $2(5 \%)$ after $48 \mathrm{~h}$ and 1 (2\%) within 7 days. In 25 patients $(53 \%)$ a good recovery was recorded at the last follow-up visit. Outcome was mainly influenced by the following factors: age, severity of TBI, and neurological status. Overall, in $70 \%$ good clinical and neurological outcomes could be achieved.

Conclusion The results of this study confirmed that pediatric SDH is a rare, but serious condition. Despite a poor prognosis, most patients could be treated with good outcomes, given that the choice of treatment is correct.

Trial registration Research registry 2686

Keywords Traumatic brain injury $\cdot$ Prognostic factors · Outcome · Glasgow coma scale · Rotterdam score

$\begin{array}{ll}\text { Abbreviations } \\ \text { AIS } & \text { Abbreviated injury scale } \\ \text { CA } & \text { Child abuse } \\ \text { CT } & \text { Computed tomography } \\ \text { EDH } & \text { Epidural hematoma } \\ \text { GCS } & \text { Glasgow coma scale } \\ \text { ICP } & \text { Intracranial pressure } \\ \text { ICU } & \text { Intensive care unit } \\ \text { ISS } & \text { Injury severity score } \\ \text { MRI } & \text { Magnetic resonance imaging } \\ \text { SDH } & \text { Subdural Hematoma } \\ \text { TBI } & \text { Traumatic brain injury }\end{array}$




\section{Introduction}

Trauma is still the leading cause of death in children. Severely injured young patients often present a traumatic brain injury (TBI) which is a frequent cause of mortality [1, 2]. Despite this, pediatric TBI is a very rare injury and physicians often rely on their clinical experience as opposed to clinical literature when making treatment decisions [3]. Acute subdural hematoma (SDH) in children, especially in infants and toddlers, is relatively uncommon, with reported incidences of 20-25 cases per 100,000 children [4]. Between 42 and $82 \%$ of infantile SDH are believed to result from child abuse (CA), which is considered to bear a poorer prognosis $[5,6]$. Due to its rare occurrence $[7,8]$ pediatric $\mathrm{SDH}$ is a challenging condition to treat. The outcome of pediatric subdural hematoma is worse than that of epidural hematoma, with mortality rates ranging from $42-90 \%$; subdural hematoma associated with child abuse is associated with a $20 \%$ mortality rate and a $50 \%$ rate of neurological morbidity [9].

Since the implementation of computed tomography (CT), accurate detection of SDH has become easier. However, variations in treatment and outcome make it difficult to draw a clear picture of traumatic SDH in children and infants $[10,11]$.

The aim of this study was to compare operative versus conservative treatment in infants and children with traumatic SDH with regard to severity and outcome.

\section{Methods}

\section{Data collection}

In a retrospective single center study, all patients with traumatic SDH under the age of 16 years treated between 1992 and 2010 were included. In total, 47 patients were included. The following patient data were extracted and presented in charts: patients demographics (age, sex), cause of injury, injury severity (Injury Severity Score (ISS), Glasgow Coma Scale (GCS), and additional injuries), CT findings, treatment modalities (surgical vs. conservative, types of surgery, additional treatment) and outcomes (GOS) at discharge and at follow-up.

\section{Treatment procedures}

Treatment procedure in all patients included rapid examination by an emergency physician (pediatric GCS and pupillary reactivity). Further medical treatment included rapid sequence intubation, ventilation, treatment of hemorrhage, treatment of associated substantial extracranial injury and fluid resuscitation, as deemed appropriate.

In the next step a CT scan was performed in every patient. Examination was performed by a trauma team of anesthesiologists, trauma surgeons and/or neurosurgeons, radiologists and nurses. Depending on the CT result, further treatment, including surgery and/or ICU admission, was undertaken. Trauma surgeons carried out neurosurgery (burr hole trepanation, craniectomy and craniotomy) in collaboration with neurosurgeons for complex issues.

Prehospital parameters and treatment were documented by paramedics. The CT findings were analyzed by a team of trauma surgeons, neurosurgeons and radiologists specialized in trauma diagnostics. In all patients with hemorrhage the Rotterdam score was calculated [12].

\section{Data analysis}

Data analysis focused on surgically versus conservatively treated patients with SDH. Patients were divided into an operated group (at least one cranial surgery) and conservative group. The following parameters

Table 1 Demographic characteristics of patients and characteristics of trauma in conservatively and surgically managed pediatric TBI patients with $\mathrm{SDH}$

\begin{tabular}{|c|c|c|c|c|c|}
\hline Measure & Conservative & Delayed surgery & Surgical & Total & $P$ value \\
\hline Total N (\%) & 26 (55\%) & 10 (21\%) & $11(23 \%)$ & 47 & - \\
\hline Age (years median, IQR) & $3.5(1-4.9)$ & $4(1-7.25)$ & $2(1.5-8.5)$ & $4(1-8.5)$ & 0.911 \\
\hline Sex ( $N$, \% male) & $12(46 \%)$ & $7(70 \%)$ & $4(36 \%)$ & $23(49 \%)$ & 0.279 \\
\hline \multicolumn{6}{|l|}{ Trauma mechanism (N, \%) } \\
\hline Battered child syndrome & $2(8 \%)$ & $2(20 \%)$ & 0 & $4(9 \%)$ & 0.454 \\
\hline Fall $(50-150 \mathrm{~cm})$ & $7(27 \%)$ & $3(30 \%)$ & 0 & $10(21 \%)$ & - \\
\hline Fall $(<50 \mathrm{~cm})$ & $1(4 \%)$ & 0 & 0 & $1(2 \%)$ & - \\
\hline Fall $(>150 \mathrm{~cm})$ & $7(27 \%)$ & $2(20 \%)$ & $7(64 \%)$ & $16(34 \%)$ & - \\
\hline Traffic accident & $4(15 \%)$ & $1(10 \%)$ & $1(9 \%)$ & $9(19 \%)$ & - \\
\hline Sports & $4(15 \%)$ & $2(20 \%)$ & $3(27 \%)$ & $6(13 \%)$ & - \\
\hline Other & $1(4 \%)$ & 0 & 0 & $1(2 \%)$ & - \\
\hline Polytrauma (N, \% Yes) & $14(54 \%)$ & $10(100 \%)$ & $11(100 \%)$ & $35(75 \%)$ & $<0.01$ \\
\hline
\end{tabular}


Table 2 Injury severity indicators in conservatively and surgically managed pediatric TBI patients with SDH

\begin{tabular}{|c|c|c|c|c|c|}
\hline Measure/Treatment type & Conservative & Delayed surgery & Surgical & Total & $P$ value \\
\hline Total N (\%) & $26(55 \%)$ & $10(21 \%)$ & $11(23 \%)$ & 47 & - \\
\hline \multicolumn{6}{|l|}{ Symptoms indicating TBI (N, \% Yes) } \\
\hline Swellings & $13(50 \%)$ & $4(40 \%)$ & $4(36 \%)$ & $21(45 \%)$ & 0.706 \\
\hline Nausea & $6(23 \%)$ & $4(40 \%)$ & 0 & $10(21 \%)$ & $<0.01$ \\
\hline Vomiting & $6(23 \%)$ & $3(30 \%)$ & $3(27 \%)$ & $12(26 \%)$ & 0.303 \\
\hline Unconsciousness ( $N$, \% present) & $11(42 \%)$ & $5(50 \%)$ & $10(91 \%)$ & $26(55 \%)$ & $<0.01$ \\
\hline \multicolumn{6}{|l|}{ Neurological status (N, \%) } \\
\hline Normal & $12(46 \%)$ & $1(10 \%)$ & 0 & $13(28 \%)$ & $<0.01$ \\
\hline Somnolent & $9(35 \%)$ & $6(60 \%)$ & $3(27 \%)$ & $18(38 \%)$ & - \\
\hline Comatose & $5(19 \%)$ & $3(30 \%)$ & $8(73 \%)$ & $16(34 \%)$ & - \\
\hline \multicolumn{6}{|l|}{ Pupils (N, \%) } \\
\hline Both reactive & $21(81 \%)$ & $5(50 \%)$ & $5(46 \%)$ & $31(66 \%)$ & 0.11 \\
\hline One reactive & $3(12 \%)$ & $4(40 \%)$ & $3(27 \%)$ & $10(21 \%)$ & - \\
\hline None reactive & $2(8 \%)$ & $1(10 \%)$ & $3(27 \%)$ & $6(13 \%)$ & - \\
\hline ISS (median, IQR) & $12.5(9-16)$ & $25(25-25)$ & $25(20-31.5)$ & $16(9-25)$ & $<0.001$ \\
\hline First pediatric GCS (median, IQR) & $3.5(1-8.75)$ & $4(1-7.25)$ & $2(1.5-8.5)$ & $4(1-8.5)$ & 0.911 \\
\hline Admission pediatric GCS (median, IQR) & $3.5(1-8.75)$ & $4(1-7.25)$ & $2(1.5-8.5)$ & $4(1-8.5)$ & 0.912 \\
\hline \multicolumn{6}{|l|}{ Vertebral fracture $(N, \%)$} \\
\hline Neck Region & $1(4 \%)$ & 0 & 0 & $1(2 \%)$ & 0.669 \\
\hline Thorax Region & 0 & 0 & 0 & 0 & - \\
\hline \multicolumn{6}{|l|}{ Additional Injuries (N, \%) } \\
\hline Upper extremity Fracture & $1(4 \%)$ & $1(10 \%)$ & $1(9 \%)$ & $3(6 \%)$ & 0.256 \\
\hline Lower Extremity Fracture & $1(4 \%)$ & $1(10 \%)$ & $3(27 \%)$ & $5(10 \%)$ & 0.134 \\
\hline Injury to thoracic region & $1(4 \%)$ & $1(10 \%)$ & $4(36 \%)$ & $6(12 \%)$ & 0.182 \\
\hline Injury to abdominal region & 0 & 0 & $2(18 \%)$ & $2(4 \%)$ & 0.032 \\
\hline \multicolumn{6}{|l|}{ Rotterdam CT Score (N, \%) } \\
\hline 1 & $2(8 \%)$ & 0 & 0 & $2(4 \%)$ & 0.049 \\
\hline 2 & $12(46 \%)$ & $2(20 \%)$ & $1(9 \%)$ & $15(32 \%)$ & - \\
\hline 3 & $8(31 \%)$ & $3(30 \%)$ & $4(36 \%)$ & $15(32 \%)$ & - \\
\hline 4 & $3(12 \%)$ & $4(40 \%)$ & $3(27 \%)$ & $10(21 \%)$ & - \\
\hline 5 & $1(4 \%)$ & 0 & $3(27 \%)$ & $4(9 \%)$ & - \\
\hline 6 & 0 & $1(10 \%)$ & 0 & $1(2 \%)$ & - \\
\hline
\end{tabular}

$T B /$ traumatic brain injury, SDH subdural hematoma, ISS injury severity score, IQR interquartil ratio, GCS Glasgow coma scale, CT computed tomography

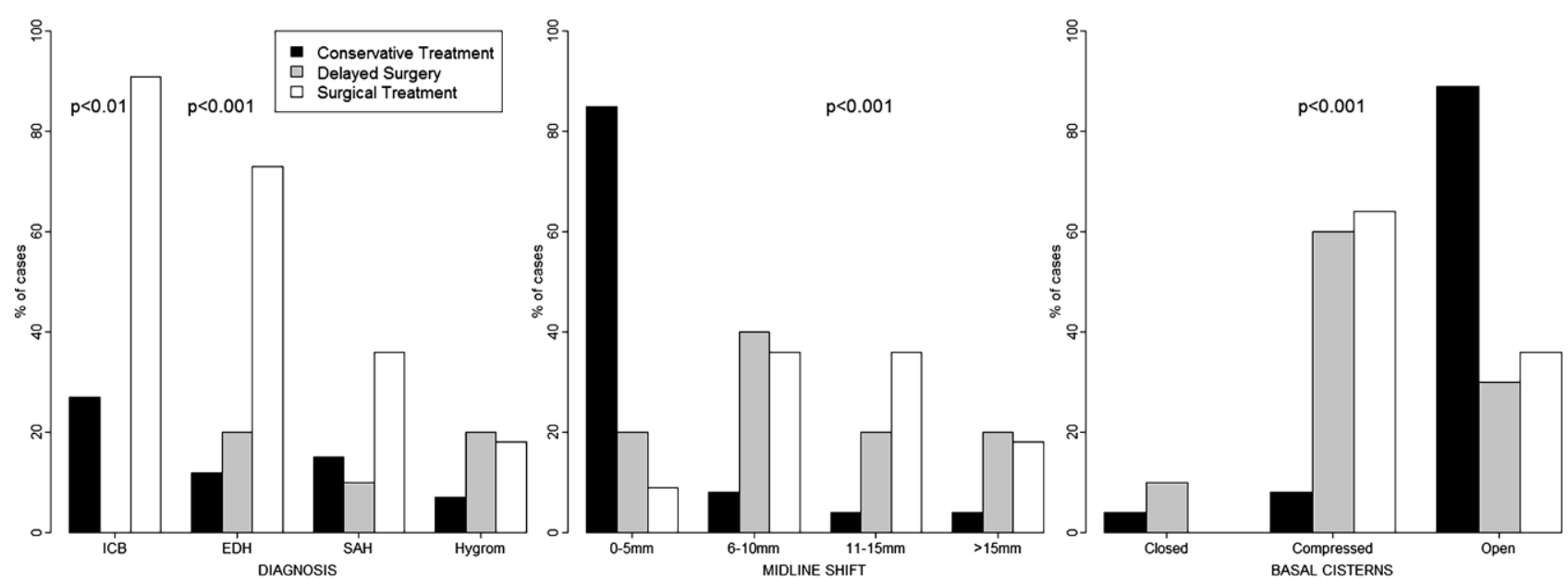

Fig. 1 Conservative versus surgically treated patients with respect to diagnosis, midline shift and compression of the basal cisterns. ICP intracranial pressure, EDH epidural hematoma, SAH subarachnoidal hematoma 
Table 3 Treatment factors in conservatively and surgically managed pediatric TBI patients with SDH

\begin{tabular}{|c|c|c|c|c|c|}
\hline Measure/treatment type & Conservative & Delayed surgery & Surgical & Total & $P$ value \\
\hline Total N (\%) & $26(55 \%)$ & $10(21 \%)$ & $11(23 \%)$ & 47 & - \\
\hline Transport (N, \% Air) & $7(27 \%)$ & $1(10 \%)$ & $6(55 \%)$ & $14(30 \%)$ & 0.018 \\
\hline Intubation (N, \%) & $5(19 \%)$ & $4(40 \%)$ & $7(64 \%)$ & $16(34 \%)$ & 0.031 \\
\hline$X$-ray done (N, \%) & $21(81 \%)$ & $5(50 \%)$ & $8(73 \%)$ & $34(72 \%)$ & 0.181 \\
\hline CT scan done (N, \%) & $26(100 \%)$ & $10(100 \%)$ & $11(100 \%)$ & $47(100 \%)$ & - \\
\hline MRI done (N, \%) & $6(23 \%)$ & $1(10 \%)$ & $1(9 \%)$ & $8(17 \%)$ & 0.469 \\
\hline \multicolumn{6}{|l|}{ ICU days (N, \%) } \\
\hline No admission & $16(62 \%)$ & 0 & 0 & $16(34 \%)$ & \multirow[t]{5}{*}{0.016} \\
\hline$\leq 10$ days & $9(35 \%)$ & $7(70 \%)$ & $5(45 \%)$ & $21(45 \%)$ & \\
\hline $11-20$ days & 0 & $1(10 \%)$ & $1(9 \%)$ & $2(4 \%)$ & \\
\hline $21-30$ days & $1(4 \%)$ & $1(10 \%)$ & $3(27 \%)$ & $4(9 \%)$ & \\
\hline Over 30 days & 0 & $1(10 \%)$ & $3(27 \%)$ & $4(9 \%)$ & \\
\hline
\end{tabular}

were analyzed between the two groups: demographic characteristics, injury cause, severity and outcome.

In cases of continuous variables medians with respective interquartile ranges were calculated and used as central measures. In cases of categorical variables total values with corresponding percentages were calculated as measures of frequency. In order to estimate the population proportions, $95 \%$ confidence intervals were calculated wherever percentages were used.

Statistical analyses were performed using the $R$ project statistical environment ( $R$ package version 0.4, Bell Laboratories [formerly AT\&T, now Lucent Technologies]; Hewson, B. 2015). A $p$-value of $<0.05$ was considered statistically significant.

\section{Results}

An overview of patient demographics and injury causes is presented in Table 1.

The median age was 4 years in the operated group and 3.5 years in the conservative group. Regarding gender, male was shown to be prevalent in the conservative group. In the operated group falls from over $150 \mathrm{~cm}$ and traffic accidents were more frequent compared to falls between $50-150 \mathrm{~cm}$, which were more common in the conservative group. Female cases of SDH were more frequently observed in toddlers compared to babies, while in the male group no differences were observed. It was an increasing number of high impact traumas with increasing age detected, which suggests an association. (Table 2).

All operated patients had additional severe injuries of which $71 \%$ were unconscious, $52 \%$ were comatose and the same proportion had at least 1 unreactive pupil. The median ISS was significantly higher in the operated group (median 25 vs. 12.5). A Rotterdam CT score of 3 or higher was observed in $85 \%$ of patients in the operated group compared to $47 \%$ in the conservative group. The CT findings (presence of additional diagnoses, midline shift and/or compression of basal cisterns) comparing surgical and conserva-
Table 4 Treatment factors in surgically managed pediatric TBI patients with SDH

\begin{tabular}{|c|c|c|c|c|}
\hline Measure & $\begin{array}{l}\text { Delayed } \\
\text { surgery }\end{array}$ & Surgical & Total & $P$ value \\
\hline Surgery time $(N, \%)$ & $10(48 \%)$ & $\begin{array}{l}11 \\
(52 \%)\end{array}$ & 21 & - \\
\hline$<1 \mathrm{~h}$ & 0 & $\begin{array}{l}11 \\
(100 \%)\end{array}$ & $\begin{array}{l}11 \\
(52 \%)\end{array}$ & $<0.001$ \\
\hline$<24 h$ & $7(70 \%)$ & 0 & $7(33 \%)$ & - \\
\hline$<1$ week & $1(10 \%)$ & 0 & $1(5 \%)$ & - \\
\hline Delayed after $4 \mathrm{~h}$ & $2(20 \%)$ & 0 & $2(10 \%)$ & - \\
\hline \multicolumn{5}{|c|}{ Number of TBI surgeries within $24 h(N, \%)$} \\
\hline One & $9(90 \%)$ & $\begin{array}{l}10 \\
(91 \%)\end{array}$ & $\begin{array}{l}19 \\
(90 \%)\end{array}$ & 1 \\
\hline Two & 0 & $2(19 \%)$ & $2(10 \%)$ & - \\
\hline \multicolumn{5}{|c|}{ Overall number of TBI surgeries ( $N, \%)$} \\
\hline One & $8(80 \%)$ & $6(55 \%)$ & $\begin{array}{l}14 \\
(66 \%)\end{array}$ & 0.023 \\
\hline Two & 0 & $5(46 \%)$ & $5(24 \%)$ & - \\
\hline Four & $2(20 \%)$ & 0 & $2(10 \%)$ & - \\
\hline \multicolumn{5}{|l|}{ Other surgery $(N, \%)$} \\
\hline Multiple surgery & 0 & $1(9 \%)$ & $1(5 \%)$ & 1 \\
\hline Osteosynthesis (external) & $1(10 \%)$ & $1(9 \%)$ & $2(10 \%)$ & - \\
\hline Mediastinal drain & 0 & $1(9 \%)$ & $1(5 \%)$ & - \\
\hline $\begin{array}{l}\text { Parenchymal ICP monitor } \\
(N, \%)\end{array}$ & $5(50 \%)$ & $\begin{array}{l}10 \\
(91 \%)\end{array}$ & $\begin{array}{l}15 \\
(71 \%)\end{array}$ & 0.063 \\
\hline Ventricular drain (N, \%) & $1(10 \%)$ & 0 & $1(5 \%)$ & 0.472 \\
\hline \multicolumn{5}{|c|}{ Days of ICP monitoring (N, \%) } \\
\hline$\leq 10$ days & $4(40 \%)$ & $6(55 \%)$ & $\begin{array}{l}10 \\
(47 \%)\end{array}$ & 0.145 \\
\hline $11-20$ days & $1(10 \%)$ & $1(9 \%)$ & $2(10 \%)$ & - \\
\hline $21-30$ days & 0 & $2(18 \%)$ & $2(10 \%)$ & - \\
\hline $30+$ days & 0 & $1(9 \%)$ & $1(5 \%)$ & - \\
\hline None & $5(50 \%)$ & $1(9 \%)$ & $6(29 \%)$ & - \\
\hline
\end{tabular}


Fig. 2 Intracranial pressure (in $\mathrm{mm} \mathrm{Hg}$ ) recorded at time of surgery

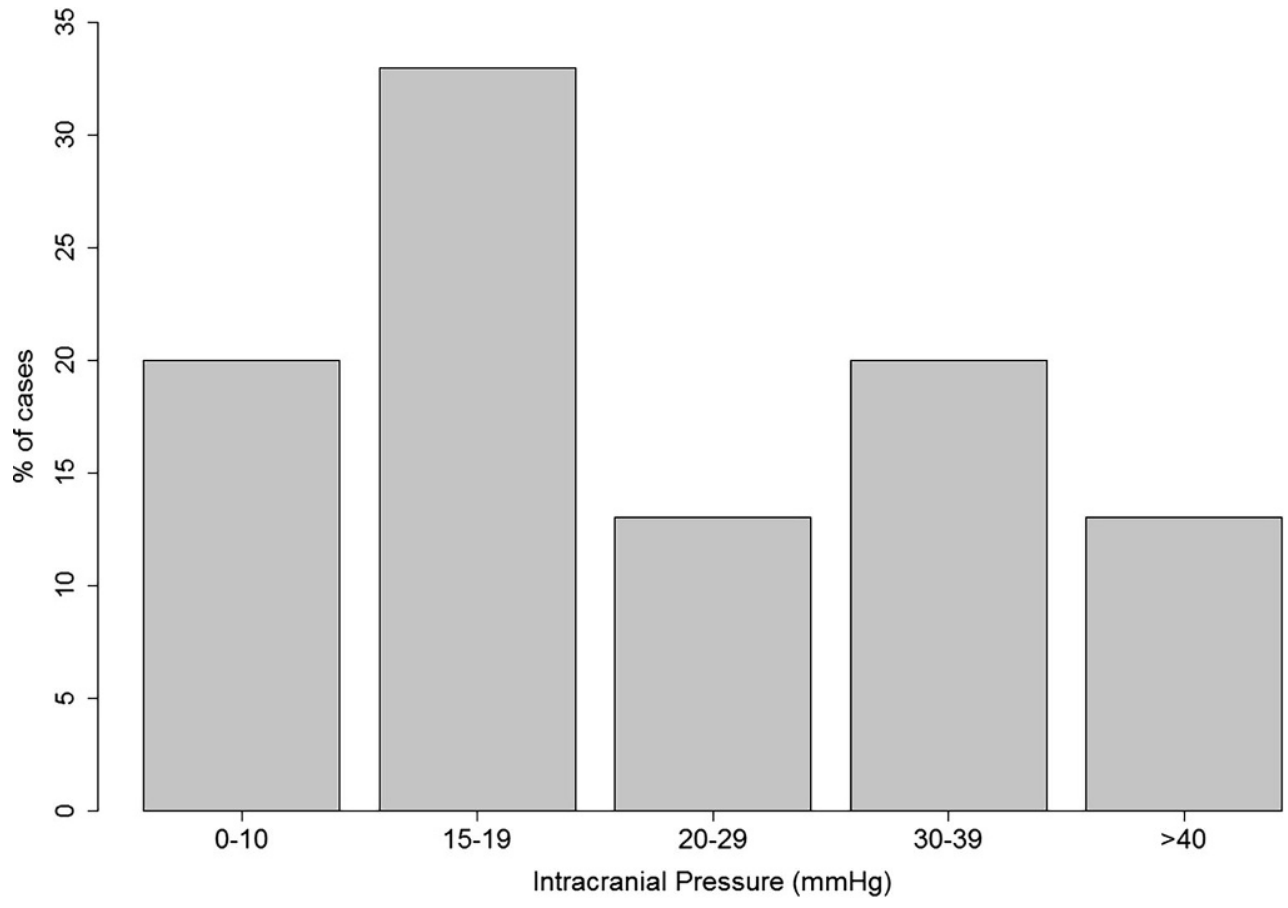

tive treatment are shown in Fig. 1., suggesting more severe injuries in the operation group. An overview of treatment factors is shown in Table 3.

There was no statistically significant difference regarding the mode of transport (air vs. ground) in the two groups; however, patients in the operative group were significantly more often intubated in the field (52\% vs. $19 \%)$ and had a significantly longer stays in the ICU (23\% stayed longer than 20 days vs. $4 \%$ in the conservative group). In the operated group $50 \%$ of patients were treated within $1 \mathrm{~h}$ after admission, whereby $25 \%$ needed a second surgical intervention and 2 patients $(10 \%)$ even required 4 operations. In this patient collective two factors accounting for delayed surgery were found: (1) severely injured patients and (2) failed conservatively managed patients (for details see Table 2 and 4 ). In total ICP was recorded in $71 \%$ of patients (Table 4, Fig. 2).

Removal of ICP monitoring is standardized when ICP parameters show no value $>10 \mathrm{~mm} \mathrm{Hg}$ in $24 \mathrm{~h}$. This is part of the policy of the investigating center, which aims to minimize the risk of postoperative infections.

Regarding outcome a significant difference in the evaluated GOS at hospital discharge between the two groups was found; however, at the latest follow-up no differences in GOS were found (Table 5).

Most patients showed a favorable outcome (moderate disability or good recovery) both at discharge $(53 \%)$ and at follow-up $(68 \%)$. The proportion of unfavorable outcome (death, vegetative state and severe disability) was higher in the operative group, especially at hospital discharge. In the surgically treated group, 4 patients (19\%) died, 2 within $48 \mathrm{~h}$ and 2 within 7 days after hospital admission. In the con- servatively treated group, 1 patient (4\%) died within $24 \mathrm{~h}$ after hospital admission. The overall mortality rate of SDH in infants and children in the sample was $11 \%$. In $52 \%$ of the patients educational achievements could be evaluated at the latest follow-up visit. In $61 \%$ of the patients a normal academic performance could be achieved. With respect to the neurocognitive function, patients who underwent surgery tended to have an unfavorable outcome.

\section{Discussion}

Summarizing the results, the following factors were associated with surgical treatment: low GCS scores, high ISS, worse CT findings, radiologically detectable cerebral injuries, a midline shift of more than $5 \mathrm{~mm}$, compressed or closed basal cisterns and neurological deficits; however, about $70 \%$ of the patients achieved a good recovery at final follow-up. In $61 \%$ of the patients a normal academic performance could even be reached.

The controversies about the treatment mode (surgery or conservative treatment) in pediatric $\mathrm{SDH}$ have not been resolved. There are still problems with hematoma removal in infants due to the technical difficulty of full evacuation and the potential danger of iatrogenic hemorrhage [13]. One aspect could help such decisions: while secondary risk factors influence the outcome significantly in adult brain-trauma patients [14], this effect is less apparent in children [15]. This is also supported by the data of the performed study.

Bullock et al. [16] and Rivas et al. [17] described worse outcomes in surgically treated cases with EDH 
Table 5 Outcomes in conservatively and surgically managed pediatric TBI patients with SDH

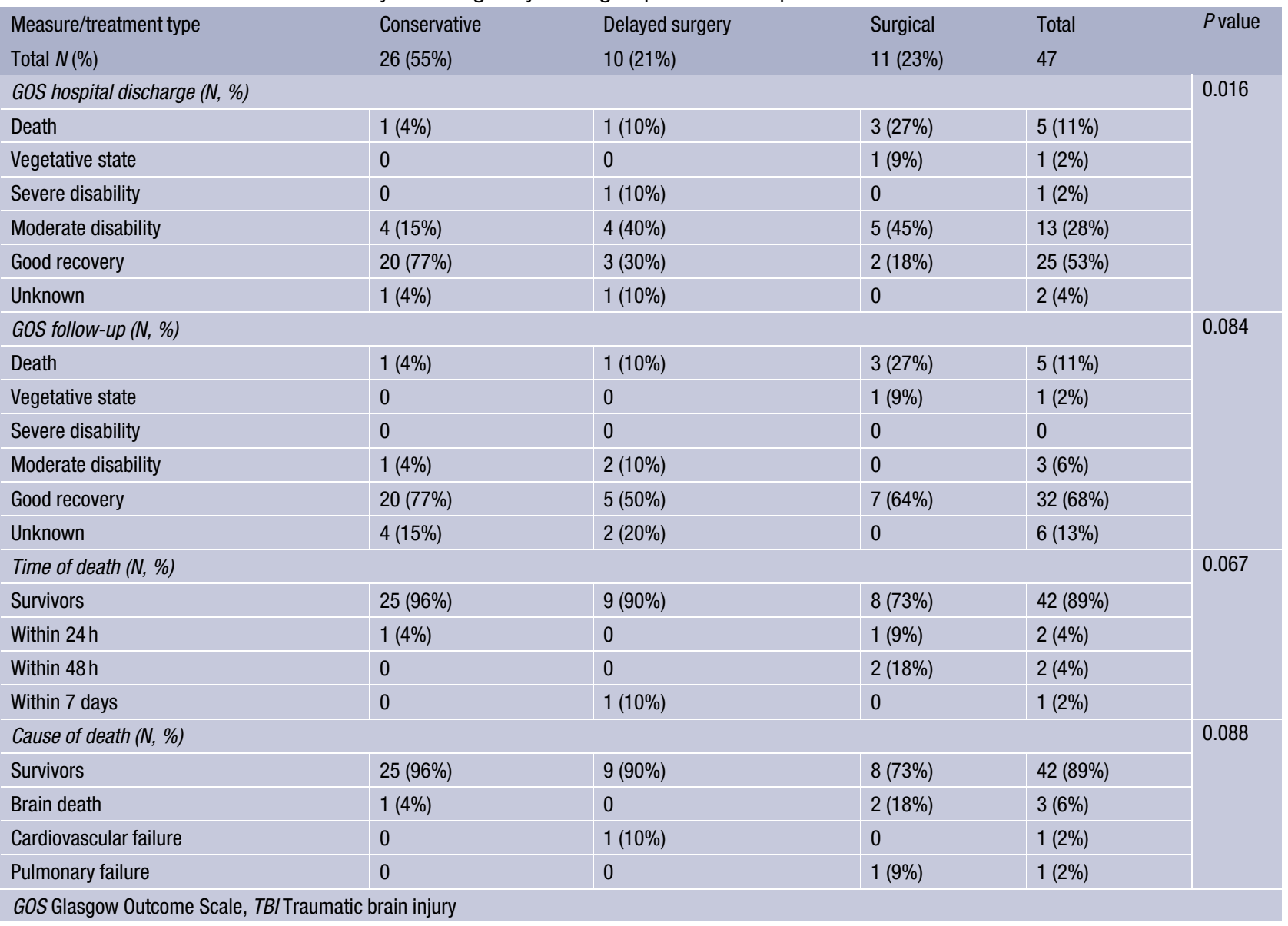

associated with SDH, which also could be proven. In the recent study, 10 patients $(48 \%)$ with $\mathrm{EDH}$ were operatively treated and 3 patients $(12 \%)$ were conservatively treated.

Conservative management was mostly performed in patients without neurological symptoms, midline shift less than $5 \mathrm{~mm}$ in the CT and open basal cisterns, presenting with good neurological outcome.

This is in accordance with the findings in other similar cohorts [15, 16].

The hospital mortality of SDH is described as being $11-36 \%$ in the literature [4], which corresponds well to the rate of $11 \%$ in the recent study.

The cause of death is additionally influenced by cardiovascular and pulmonary failure, which were the reasons of death in two operated children with polytrauma.

Although $\mathrm{SDH}$ is often regarded as a manifestation of child abuse $[8,9,18-20]$, only 4 cases $(9 \%)$ were detected. All of them were under the age of 4 years, with the two cases who died of acute brain death being under the age of 1 year serving as good examples for the poorer prognosis in infantile SDH resulting from child abuse [18]. Although only 9\% suffered from SDH due to child abuse, the absence of a history of significant accidental trauma necessitates a full investigation of maltreatment, which is also recommended in the literature [4]. Summarizing the negative prognostic factors for survival, the following were found: surgically treated SDH combined with $\mathrm{EDH}$, polytrauma, diffuse swelling as a potent precursor of cerebral herniation and SDH resulting from child abuse. No statistically significant difference concerning negative clinical results in relation to multiple surgical procedures could be detected.

There are considerable limitations to this study: it had a retrospective design and a relatively small cohort of patients, which is a consequence of the rather rare occurrence of these specific types of trauma, but nevertheless it limits the generalizability of the findings. The study represents a homogeneous patient group with the main outcome parameters reported and therefore is able to make a valid conclusion.

\section{Conclusion}

This study confirmed that pediatric SDH is a rare, but serious condition. Despite a poor prognosis, most patients could be treated with good outcomes, given that the choice of treatment was correct. In practice, the treatment decisions are to a large extent left to the physician. This could be overcome by clear treat- 
ment guidelines, the definition of which requires more studies similar to this one, ideally with data sets and a longer follow-up period.

Funding Open access funding provided by Medical University of Vienna.

\section{Compliance with ethical guidelines}

Conflict of interest H. Binder, T.M. Tiefenboeck, M. Majdan, M. Komjati, R. Schuster, S. Hajdu, and J. Leitgeb declare that they have no competing interests.

Ethical standards Ethics approval was obtained prior to study start. The corresponding ethics review board of the Medical University of Vienna approved the study.

Open Access This article is licensed under a Creative Commons Attribution 4.0 International License, which permits use, sharing, adaptation, distribution and reproduction in any medium or format, as long as you give appropriate credit to the original author(s) and the source, provide a link to the Creative Commons licence, and indicate if changes were made. The images or other third party material in this article are included in the article's Creative Commons licence, unless indicated otherwise in a credit line to the material. If material is not included in the article's Creative Commons licence and your intended use is not permitted by statutory regulation or exceeds the permitted use, you will need to obtain permission directly from the copyright holder. To view a copy of this licence, visit http://creativecommons.org/licenses/by/4.0/.

\section{References}

1. Parslow RC, Morris KP, Tasker RC, Forsyth RJ, Hawley CA. Epidemiology of traumatic brain injury in children receiving intensive care in the UK. Arch Dis Child. 2005;90(11):1182-7.

2. Tepas JJ3rd, DiScala C, Ramenofsky ML, BarlowB. Mortality and head injury: the pediatric perspective. J Pediatr Surg. 1990;25(1):92-5. discussion 96.

3. Adelson PD, Bratton SL, Carney NA, et al. Guidelines for the acute medical management of severe traumatic brain injury in infants, children, and adolescents. Chapter 1: Introduction. Pediatr CritCare Med. 2003;4(3 Suppl):S2-S4 .

4. Jayawant $S$, Parr J. Outcome following subdural haemorrhages in infancy. Arch Dis Child. 2007;92(4):343-7.

5. Maas AI, Hukkelhoven CW, Marshall LF, Steyerberg EW. Prediction of outcome in traumatic brain injury with computed tomographic characteristics: a comparison between the computed tomographic classification and combinations of computed tomographic predictors. Neurosurgery. 2005;57(6):1173-82. discussion 1173-1182.

6. Abraham BR, Lahat E, Sheinman G, et al. Metabolic and clinical markers of prognosis in the era ofCT imaging in chil- dren with acute epidural hematomas. Pediatr Neurosurg. 2000;33(2):70-5.

7. Duhaime AC, Alario AJ, Lewander WJ, et al. Head injury in very young children: mechanisms, injury types, and ophthalmologic findings in 100 hospitalized patients younger than 2 years of age. Pediatrics. 1992;90(2 Pt 1):179-85.

8. Reece RM, Sege R. Childhood head injuries: accidental or inflicted? Arch Pediatr Adolesc Med. 2000;154(1):11-5.

9. Beni-Adani L, Flores I, Spektor S, Umansky F, Constantini S. Epidural hematoma in infants: a different entity? J Trauma. 1999;46(2):306-11.

10. Jamous MA, Abdel Aziz H, Al Kaisy F, Eloqayli H, Azab M, Al-Jarrah M. Conservative management of acute epidural hematoma in a pediatric age group. Pediatr Neurosurg. 2009;45(3):181-4.

11. Cheung PS, Lam JM, Yeung JH, Graham CA, Rainer TH. Outcome of traumatic extradural haematoma in Hong Kong. Injury. 2007;38(1):76-80.

12. Maas AI, Hukkelhoven CW, Marshall LF, et al. Prediction of outcome in traumatic brain injury with computed tomographic characteristics: a comparison between the computed tomographic classification and combinations of computed tomographic predictors. Neurosurgery. 2005;57(6):1173-1182

13. Maggi G, Aliberti F, Petrone G, Ruggiero C. Extradural hematomas in children. J Neurosurg Sci. 1998;42(2):95-9.

14. Wolf H, Machold W, Frantal S, et al. Risk factors indicating the need for cranial CT scans in elderly patients with head trauma: an Austrian trial and comparison with the Canadian CT Head Rule. J Neurosurg. 2014;120(2):447-52.

15. Adelson PD, Bratton SL, Carney NA, et al. Guidelines for the acute medical management of severe traumatic brain injury in infants, children, and adolescents. Chapter 18. Nutritional support. Pediatr Crit Care Med. 2003;4(3 Suppl):S68-S71.

16. BullockMR, ChesnutR, GhajarJ, etal. Surgicalmanagement of acute epidural hematomas. Neurosurgery. 2006;58(3 Suppl):S7-S15. discussionSi-iv.

17. Rivas JJ, Lobato RD, Sarabia R, Cordobes F, Cabrera A, Gomez P. Extradural hematoma: analysis of factors influencing the courses of 161 patients. Neurosurgery. 1988;23(1):44-51.

18. Vinchon M, Defoort-Dhellemmes S, Desurmont $M$, Dhellemmes P. Accidental and nonaccidental head injuries in infants: a prospective study. J Neurosurg. 2005;102(4 Suppl):380-4.

19. Parent AD. Pediatric chronic subdural hematoma: a retrospective comparative analysis. Pediatr Neurosurg. 1992;18(5-6):266-71.

20. Duhaime AC, Christian CW, Rorke LB, Zimmerman RA. Nonaccidental head injury in infants-the "shaken-baby syndrome”. NEngl J Med. 1998;338(25):1822-9.

Publisher's Note Springer Nature remains neutral with regard to jurisdictional claims in published maps and institutional affiliations. 